\title{
O PROBLEMA DOS LIMITES ENTRE AS LITERATURAS GALEGA E PORTUGUESA NA ÉPOCA MEDIEVAL $(*)$
}

\author{
por \\ JOSÉ LUÍS RODRÍGUEZ
}

Reconhecemos antecipadamente que o assunto é complexo, e sujeito decerto a diversos ideologemas que, mesmo de modo implícito e até inconsciente, o condicionam já a priori. Parece importante, contudo, aproximarmo-nos desta problemática, se não isentos de condicionamentos, acaso de todo inevitáveis, sim pelo menos dispostos a entretecer algumas reflexões alicerçadas em critérios de racionalidade e, tanto quanto nos foi possível, de coerência.

Para começar, põe-se uma questão básica, como é a da delimitação da literatura quando aplicada a obras medievais, onde com frequência se estende a produtos não portadores de literariedade ou, pelo menos, não intencionalmente literários. É o caso, por exemplo, de tanta obra historiográfica ou de natureza edificante; é o caso, em geral, dos escritos com finalidade simplesmente didáctica. Não sendo, porém, um problema específico do Ocidente peninsular, permitimo-nos obviá-lo nesta ocasião.

Existe nos primórdios uma literatura indiscutivelmente comum à Galiza e Portugal, uma literatura (em particular uma poesia) denominada «galegoportuguesa», e por vezes (com menos propriedade) «galaico-portuguesa» ${ }^{1}$,

$\left(^{*}\right)$ Este texto foi apresentado no Seminário Luso-Galaico de Estudos (...) comemorativo do VII Centenário da concessão foral à Vila de Caminha. Câmara Municipal de Caminha, 20 a 22 de Outubro de 1984.

' Com efeito, mesmo autores do mais renuente a qualquer aproximação luso-galaica, como o Prof. Ramón Lorenzo, admitem a denominação de «galego-portuguesa» aplicada à 
desde tempos antigos, a partir de D. Carolina Michãelis de Vasconcelos nomeadamente. Esta designação, na teoria incontestável (e incontestada), assenta com certeza, entre outros, nos seguintes factores principais:

a) a existência de uma língua comum às duas margens do rio Minho ${ }^{2}$, veículo expressivo deste primeiro florescer lírico.

b) o contexto sócio-cultural, não marcado, ou não marcado de modo significativo ${ }^{3}$, pela incipiente fronteira política.

c) a pertença dos autores a uma mesma escola literária, a trovadoresca. O que implica pertença a um mesmo período literário.

d) a presença dominante no repertorio de poetas galegos e portugueses; mais ainda, de galego-portugueses (isto é, de nacionalidade

lírica trovadoresca (Cfr. Tradición, actualidade e futuro do galego. Actas do Colóquio de Tréveris. Xunta de Galicia, Consellería de Cultura, Santiago de Compostela 1982, p. 203). Alguns anos antes, aceitava ainda uma aplicação mais alargada: «Admito la expresión, si con ella se entiende cualquier texto de la época medieval, tanto la Crónica gallega, como la Crónica de 1344, la Demanda do Santo Graal o cualquier otro texto escrito en el Occidente de la Península» (La traducción gallega de la Crónica General y de la Crónica de Castilla. Ed. crítica. Instituto de Estudios Orensanos «Padre Feijoo», Orense 1975, vol. I, p. XXXVI).

Quanto ao composto galaico-português, convém notar que é um híbrido de elementos culto e popular. Compostos harmónicos serão galego-português, galaico-portucalense, luso-galaico, etc. Estudiosos tão significativos do nosso lirismo como Manuel Rodrigues Lapa ou Luciana Stegagno Picchio, muitas vezes se têm posicionado contra tal híbrido.

${ }^{2}$ Nos últimos anos, dois congressos internacionais pelo menos (Situação Actual da Lingua Portuguesa no Mundo, Lisboa, Junho de 1983, e $I^{\circ}$ Congresso Internacional da Língua Galego-Portuguesa na Galiza, Ourense, Setembro de 1984), têm avalizado com a sua autoridade a doutrina tradicional da pertença do galego e português a um mesmo sistema linguístico, a uma mesma lingua, diferenciada, porém, em normas autónomas, uma das quais a galega. Esta afirmação, referida a um estado de língua actual, faz desnecessária, como é lógico, qualquer justificação sobre a unidade medieval. Unidade real cujo reflexo literário natural é a coiné dos trovadores; unidade que não exclui a presença de preferências idiomáticas galegas ou, virtualmente trasmontanas, beiroas ou algarvias. Como a existência de matizes riojanos ou toledanos no castelhano medieval, normandos ou picardos no francês da mesma época, por pôr uns exemplos, não questiona em absoluto a unidade dessas línguas.

${ }^{3} \mathrm{~A}$ 'fronteira' minhota tardou em ser um elemento isolador entre os dois povos que foram inicialmente um só. A ordenação eclesiástica, por exemplo, não se correspondia inteiramente com a política; os nobres possuíam propriedades a um outro lado do Minho, e as relações familiares eram constantes. Basta consultar os Livros de Linhagens para patentear esta profunda imbricação galego-portuguesa. Note-se, enfim, que a própria produção trovadoresca (pelo menos conhecida) é posterior à gestação do reino de Portugal, apresentando-se assim como um facto exterior à unidade política galaico-lusa.

"CUADERNOS DE ESTUDIOS GALLEGOS", Tomo XLI, Fascículo 106, Santiago 1993-94. 
galaica ou lusitana difícil ou até impossível de determinar).

e) o surto de centros mecenáticos, criadores e irradiadores desta lírica, na Galiza e em Portugal, se bem que não só (v. gr., a corte toledana, nomeadamente).

Apesar dos sólidos alicerces científicos que exigem o traço-de-união entre os termos «galego» e «português» (se não a total fusão gráfica) para designar este córpus literário, na realidade, porém, e tanto na Galiza como em Portugal, esquece-se com frequência o gentílico referente à outra entidade, e denomina-se desta maneira literatura «galega» à obra do rei D. Denis de Portugal, e literatura «portuguesa», v. gr., à poesia de Joam Airas de Santiago ou de Afonso X, o Sábio ${ }^{4}$. Num e noutro caso estamos, a rigor, perante literatura galego-portuguesa.

A qualificação pois, de, «galego-portuguesa», pacificamente aceite, mas näo inteiramente aplicada, designa a poesia dos dois povos, galego e português, até 1354, data da morte de D. Pedro, Conde de Barcelos, tida emblematicamente como indicadora da prática desaparição desta primeira lírica. Entre 1354 e 1516, em que surge o Cancioneiro Geral de Garcia de Resende, a poesia parecia ter abandonado o país do Rei Trovador, com a excepção das poucas colaborações de poetas portugueses em meios castelhanos, que, com outras, foram a princípios deste século (1902) reunidas no chamado «cancioneiro de Lang». Mas embora fosse pouca a presença portuguesa aqui consignada, isto não quer dizer que não existisse uma certa continuidade da escola trovadoresca, com autores lusos (mas sobretudo castelhanos e galegos) na corte dos monarcas da Casa de Trastâmara. E é precisamente o autor atrás aludido, Henry Lang, o responsável da etiqueta de «galego-castelhana» inadequadamente atribuída a esta etapa de prolongação da lírica trovadoresca, como têm justamente

\footnotetext{
${ }^{4}$ Eis uns poucos exemplos desta prática, já deste Teófilo Braga (v. gr.: Cancioneiro «Portuguez» da Vaticana. Lisboa 1878), mas presente ainda na actualidade (v. gr. a própria edição fac-símilar do manuscrito: Cancioneiro «Português» da Biblioteca Vaticana. Centro de Estudos Filológicos, Lisboa 1973, embora nestes casos a referência possa aludir à materialidade do códice). O mesmo se passa, amiúde, com investigadores estrangeiros, v. gr.: Wilhelm Storck (Hundert altportugiesisches Lieder. Padeborn und Münster 1885), Aubrey F. G. Bell (The Oxford Book of Portuguese Verse. XII Century. Oxford 1925) e outros (Poesia «Gallega» Medioeval. De los siglos XII al XV. Emecé Ed., Buenos Aires 1941).
}

"CUADERNOS DE ESTUDIOS GALLEGOS", Tomo XLI, Fascículo 106, Santiago 1993-94. 
notado alguns estudiosos ${ }^{5}$. Também é conhecido que investigadores italianos, como Giuseppe Tavani ou Luciana Stegagno Picchio, acrescentaram o contributo português a este período com a descoberta do carácter tardio de certos textos, inseridos espuriamente na tradição manuscrita galegoportuguesa ${ }^{6}$, e por isto atribuídos às vezes a autores da época dourada do trovadorismo, como, por exemplo, D. Denis ou Juião Bolseiro. Repare-se, por outra parte, que o Cancioneiro de Garcia de Resende recolhe composições a partir dos meados do séc. $X^{7}$. Não se produz, pois, propriamente, um «interregno» poético, como tantas vezes se tem repetido. Sobrevém, em todo o caso, e desconsiderando os textos probabilissimamente perdidos ${ }^{8}$, um período de decadência de um século de duração. Mas não existe interrupção. Pelo contrário, verifica-se uma natural evolução da poesia trovadoresca 'primeira', que continuará a ser cultivada por autores de diferente nacionalidade, em diversos centros, num clima sóciocultural uniforme no essencial, e com uns ideais estético-literários também basicamente comuns. Sem descurar as diferenças (de intensidade, sobretudo), cremos manterem-se no essencial os factores indicados ini-

\footnotetext{
${ }^{5}$ Assim, v. gr., Pilar Vázquez Cuesta: «Pero el hecho de haber titulado Lang a la recopilación de poesías en galaico-portugués dispersas en Cancioneros castellanos del siglo XV que publica en 1902 determinaría que se diese a esta etapa de decadencia de la tradición lírica galaicoportuguesa el nombre de gallego-castellana, con lo que ha sido descuidada por algunos historiadores de la literatura portuguesa» («Literatura gallega», in Historia de las literaturas hispánicas no castellanas, dirigida por José María Díaz Borque. Taurus Ed., Madrid 1980, p. 634).

${ }^{6}$ Trata-se de composições que se situam na primeira metade do séc. XV. Vid. entre outros os trabalhos modelares de G. Tavani e de L. Stegagno Picchio recolhidos, respectivamente, em Poesia del Duecento nella Penisola Iberica (Ed. dell'Ateneo, Roma 1969, pp. 183 e ss.) e em $A$ Lição do Texto (Edições 70, Lisboa 1979, pp. 111 e ss.).

${ }^{7}$ A peça datável mais antiga é um louvor a Juan de Mena da autoria do Infante-Regente D. Pedro (morto em Alfarrobeira em 1449).

${ }^{8}$ Que se experimentaram perdas no nosso espólio poético demonstra-o, por exemplo, o facto de chegarem a nós nomes de autores, e dos considerados importantes (como Joam Lourenço da Cunha, Fernam Casquício ou Vasco Perez de Camões), de cuja obra não restam vestígios. Mais ainda, a dar crédito à boa memória do Marquês de Santillana na sua famosa Carta-Proémio ao Condestável D. Pedro de Portugal, o Cancionero por ele visto em casa da sua avó, D. Mencía de Cisneros, «un grant volumen de cantigas serranas e decires portugueses e gallegos», poderia ser, pelo seu conteúdo, radicalmente diverso dos conhecidos hoje (cfr. porém as prudentes considerações de C. Michaẽlis, no Cancioneiro da Ajuda. Halle 1904, vol. II, pp. 239 e ss.).
}

"CUADERNOS DE ESTUDIOS GALLEGOS", Tomo XLI, Fascículo 106, Santiago 1993-94. 
cialmente como justificadores da denominação de "galego-portuguesa» para a nossa lírica trovadoresca. Em consequência, acaso não seja descabido qualificar assim, «galego-portuguesa», toda a poesia da Galiza e de Portugal na Idade Média, a qual é susceptível, contudo, de uma nítida periodização. Filgueira Valverde ${ }^{9}$ viu-a em três etapas ou épocas fundamentais:

- Origens (Época primitiva). Até $1198^{10}$. Isto é, a pré-história.

- Florescimento. Entre 1198 e 1354. Período de esplendor do lirismo trovadoresco.

- Decadência. Que vai até 1445 e depois se prolonga até ao primeiro terço do séc. XVI.

Este autor e P. Vázquez Cuesta, mais recentemente ${ }^{11}$, coincidem em prolongar os limites do grande movimento lírico até aos princípios do séc. XVI. Com efeito, parece-nos que a data de 1516, significativa por assinalar a publicação do Cancioneiro de Resende, pode servir perfeitamente como termo ad quem, improrrogável, da lírica galego-portuguesa. A total ausência de autores galegos nas elaborações lusitanas posteriores (e já no cancioneiro citado), a absoluta decadência no campo da literatura que, por razões extra-literárias, vai sofrer durante séculos a Galiza, e o seu próprio idioma, que padecerá uma aberta remodelação em termos castelhanizantes, e para mais o influxo italiano e greco-latino propiciado pelo Renascimento, que

${ }^{9}$ «Lírica medieval gallega y portuguesa», in Historia General de las Literaturas Hispánicas, dirigida por Guillermo Díaz Plaja. Ed. Barna, Barcelona 1949, p. 545. Note-se, não obstante, como autor, neste trabalho fundamental para a altura, apesar de assinalar a unidade do desenvolvimento lírico medieval no Ocidente peninsular, dissocia no próprio título a já tradicional rubrica «galego-portuguesa» aplicada à lírica.

${ }^{10}$ Que corresponde, na intenção do autor, à data da composição mais antiga. Eugenio López Aydillo, no entanto, tinha dado com boas razões o ano de 1196 para o conhecido sirventês de Joam Soarez de Pávia contra o rei D. Sancho de Navarra («Los cancioneros gallego-portugueses como fuentes históricas», in Revue Hispanique, LVII, 1923, p. 353).

${ }^{11}$ «En su etapa medieval resulta completamente imposible distinguir la poesía gallega de la portuguesa» (Op. cit., p. 630). «En cuanto al ámbito cronológico se extiende desde finales del siglo XII hasta mediados del XV o comienzos del XVI, si nos reducimos a la literatura escrita» (ibid., p. 633). Autores como Alvaro J. da Costa Pimpão e, assim mesmo, António José Saraiva - Oscar Lopes, nas suas respectivas histórias da literatura (Ed. Quadrante, Coimbra 1947, pp. 345-348; Porto Ed., Porto, s. d., 6 $6^{a}$ ed., pp. 151-153), levam, implícita ou explicitamente, o lirismo trovadoresco galego-português até 1450. O Cancioneiro Geral de Resende, no entanto, explicita-se na sua maior parte em termos estético-literários tradicionais, de proveniência trovadoresca.

"CUADERNOS DE ESTUDIOS GALLEGOS", Tomo XLI, Fascículo 106, Santiago 1993-94. 
fertilizam o vernáculo em Portugal gerando caminhos novos, constituem factores que marcam uma profunda quebra com o passado medieval. Cremos, sem hesitação, que a partir desta altura é preciso falar de líricas galega e portuguesa perfeitamente diferenciadas, de rumos indiscutivelmente autónomos.

Se da poesia passarmos à prosa, os problemas parecem ser ainda maiores. Para começar é aqui que melhor cabe, no nosso caso, a advertência preliminar sobre o carácter literário ou não literário das produções medievais, o que divide o córpus prosístico da Idade Média em dois tipos, pelo menos teóricos: textos literários e textos não literários; todavia, dada a dificuldade de estabelecer uma fronteira nítida entre os dois especimes, é preferível distinguir simplesmente entre textos novelísticos ou, com mais amplitude, ficcionais em maior ou menor grau, e textos de natureza utilitária. Focaremos prioritariamente os primeiros, por caírem, de maneira mais específica, no campo da literatura.

É frequente distinguir entre obras galego-portuguesas ${ }^{12}$, por uma parte, e obras galegas e obras portuguesas, por outra. No primeiro grupo incluemse, normalmente, os textos pertencentes ao ciclo bretão ou arturiano (o José de Arimatea, a Demanda do Santo Graal, ambos em cópias tardias, um fragmento do Tristam e outro de Merlim; enfim, o hipotético Amadis de Gaula em galego-português), assim com algumas obras de tipo historiográfico, a maioria delas adaptações ou continuações do ímpar modelo do Rei Sábio, como as versões da Crónica General y Crónica de Castilla e da General Estoria, os Livros de Linhagens, a perdida Crónica do Mouro Rasis ou a Crónica Geral de Espanha de 1344. Características comuns a todas estas obras para justificarem a denominação de «galego-portuguesas», para além da indiscutível unidade linguística ${ }^{13}$, parecemos ser:

12 «La prosa medieval gallega se desenvuelve en dos etapas (...). Hay una primera etapa en el desenvolvimiento de la prosa que coincide con el de la poesía. No se puede separar en esta etapa lo gallego de lo portugués. La prosa de este tiempo, el período trovadoresco, debe denominarse también gallego-portuguesa» (Ricardo Carballo Calero: Historia de las literaturas hispánicas. Unidad didáctica 1. Universidad Nacional de Educación a Distancia, Madrid 1977, p. 52). Com relação aos textos historiográficos, há autores, contudo, que individuam já neles uma precoce adscrição galega ou portuguesa.

${ }^{13}$ Remetemos para a nota 2. Com respeito, por exemplo, ao texto de Tristam, o seu editor, o Prof. José Luis Pensado (Fragmento de um Livro de Tristán galaico-portugués. Santiago de Compostela 1962), apesar de oferecer um apurado estudo da língua, detém-se na qualificação de «galaico-portugués», renunciando a mais especificações desajuizadas. O mesmo faz ao editar textos fragmentários de teor jurídico («Tres fragmentos jurídicos

"CUADERNOS DE ESTUDIOS GALLEGOS", Tomo XLI, Fascículo 106, Santiago 1993-94. 
a) a contemporaneidade desta produção com o florescimento lírico trovadoresco.

b) a sua autoria galega, portuguesa ou galego-portuguesa (isto é, de nacionalidade galaica ou lusa imprecisável).

c) a existência de interpenetração cultural por cima, e apesar, das barreiras fronteiriças ${ }^{14}$.

d) o facto de serem, em geral, obras de criação ou produçäo secundária, quer dizer, dependentes, em maior ou menor grau, de outros textos (latinos, castelhanos ou franceses).

De todas estas características assinaladas, a mais eloquente (com exclusão da comum base linguística) acaso seja a primeira, por uma natural coerência com respeito ao lirismo. Com efeito, não pareceria lógico que o Conde de Barcelos, por exemplo, como poeta pertencesse à literatura galego-portuguesa, mas como prosista, como presumível autor ou orientador do Livro de Linhagens (o terceiro) e da Crónica Geral de Espanha de 1344, se incluísse unicamente na literatura portuguesa. Outra vez estamos, com exactidão, perante literatura galego-portuguesa.

Passemos agora a uma breve consideração sobre as obras galegas e portuguesas posteriores, grosso modo, a 1350. Na Galiza avulta, dentro do ciclo clássico, a Crónica Troiana, assim como, já no chamado ciclo carolíngio, os Miragres de Santiago, «la verdadera joya de la prosa gallega medieval», em opinião de P. Vázquez Cuesta ${ }^{15}$. Há também uma certa continuidade historiográfica (a Crónica Galega de 1404, e a Corónica de Santa Maria de Iria, algo posterior), de reduzido interesse literário. Em Portugal, contrariamente, órfão quase da produção ficcional do primeiro

galaicoportugueses», in Cuadernos de Estudios Gallegos, tomo XXIX, 87-88-89, MCMLXXIV-MCMLXXV, pp. 102-129).

${ }^{14} \mathrm{Cfr}$. nota 3. A versão galego-portuguesa da Crónica General e da Crónica de Castilla, realizada por um autor galego, serviu de fonte fundamental para a Crónica Geral de Espanha de 1344 do Conde D. Pedro, obra esta básica para a historiografia lusitana posterior. A relação, provada por Luís F. Lindley Cintra (Crónica Geral de Espanha de 1344. Ed. crítica, Lisboa 1951, vol. I, pp. CCCXVII-CCCIII), levou Diego Catalán a situá-la, quanto à autoria, na hipotética órbita do Conde de Barcelos, decerto com pouca base (cfr. R. Lorenzo: Op. cit., vol. I, pp. XIX-XXIV). Em todo o caso, o aproveitamento do texto de autoria galega, como intermediário entre os castelhanos e a Crónica do Conde, implica uma natural relação, na época, entre galegos e portugueses, não obscurecida por pequenas dissonâncias de cor local, nem pelo diferente marco político em que se verificava.

${ }^{15}$ Op. cit., p. 703.

"CUADERNOS DE ESTUDIOS GALLEGOS", Tomo XLI, Fascículo 106, Santiago 1993-94. 
tipo, brilha, como se sabe, o labor ingente dos cronistas do reino, com a figura gigante de Fernão Lopes à sua frente. Há, assim mesmo, diferenças de ordem cronológica: os textos galegos fundamentais são do séc. XIV ( $2^{\mathrm{a}}$ metade), o córpus do Cronista é do séc. XV ( $1^{\mathrm{a}}$ metade). Aliás, enquanto as obras galegas continuam a ser ainda, basicamente, de carácter secundário, a produção de Fernão Lopes, de forte originalidade, é, em consequência, de tipo primário, o que a predispõe para uma maior presença do especificamente português. Ricardo Carballo Calero, a respeito desta segunda etapa da prosa na Galiza, que chama «posterior», afirma:

"El divorcio político-cultural entre Portugal y Galicia ya se ha consumado. Si la lengua es aún la misma, con pequeñas divergencias dialectales, los problemas sociales, el sentimiento nacional, los intereses colectivos son ya distintos» ${ }^{16}$

Talvez seja algo excessivo falar em «divorcio...cultural» (político, sim). É verdade que não possuímos, desta época 'posterior', obras que atestem uma determinada colaboração galego-portuguesa, o que não quer dizer, contudo, que não possam ter existido. Há de facto testemunhos incontestáveis de que a fronteira luso-galaica continuou a ser perfeitamente permeável às relações, pelo menos humanas, entre ambos (?) os povos ${ }^{17}$. A emigração para Sul de um Vasco Perez de Camões, antepassado do Poeta, assim como a de Joam Fernandez de Andeiro, que chegaria a ser Conde de Ourém, ou os vaivéns da biografia de D. Pedro Alvarez de Soutomaior, Conde de Caminha, são, entre outros, exemplos suficientemente explícitos da atracção lusíada sobre a grei de Breogão. Como as frustradas tentativas, por parte do rei D. Fernando, de incorporar a Galiza aos seus domínios naturais ${ }^{18}$, ilustram o fenómeno inverso. Só a progressiva castelhanização da nobreza no Aquém-Minho, a partir da entronização

\footnotetext{
${ }^{16}$ Op. cit., loc. cit.

${ }^{17}$ Nunca deixou de o ser, muito embora certos assomos pontuais de «fraternidade agressiva», conforme expressão de M. Rodrigues Lapa (Estudos Galego-Portugueses. Sá da Costa, Lisboa 1979, p. 91). E a solidariedade popular, espontânea, jamais faltou, quando precisa (sobretudo em conflitos bélicos, perseguições ideológicas, ou falta de bens básicos), mesmo contra a política oficial do Estado respectivo. A bem dizer, a fronteira lusoespanhola, na sua secção norte, nunca sobrepassou a consideração (popular) de raia.

${ }^{18}$ Tentativas fracassadas, é bom frisá-lo, pela intervenção militar de Castela em Portugal, que obriga o rei $\mathrm{D}$. Fernando a embarcar da Corunha rumo a Lisboa para defender a capital. A Crónica de D. Fernando, de Fernão Lopes, desenvolve com certo pormenor a acção deste rei na Galiza.
}

"CUADERNOS DE ESTUDIOS GALLEGOS", Tomo XLI, Fascículo 106, Santiago 1993-94. 
dos Trastâmara, iria dificultando, a nível de elite, os contactos outrora fecundos. E com eles diversos interesses, antes coincidentes ou complementares, e as relações culturais, que, firmando aos poucos um estatuto de crescente estranheza, encetavam um semi-apagamento secu$\operatorname{lar}^{19}$.

Parece-nos que mesmo nesta segunda época, e até ao reinado dos Reis Católicos (1474-1504/1516), que acarretam, na prática, o emudecimento galego $^{20}$, sobrevive no essencial a maioria das características assinaladas como definitórias da prosa da primeira época, pois continuam a existir textos (menores) de autoria duvidosa, galega ou portuguesa, assim como uma interligação luso-galaica inequívoca, se bem que cada vez menos saliente. Só o último factor ali apontado, responsável de uma certa tonalidade comum, se põe decididamente em questão por causa do carácter inovador da obra de Fernão Lopes, «uma das mais belas produções de toda a historiografia europeia», na avaliação de Luís F. Lindley Cintra ${ }^{21}$.

A presença de um acusado sentimento nacional, de um afectivo (e efectivo) portuguesismo, na Crónica-Epopeia do «guardador das escrituras» da Torre do Tombo, constitui aspecto insdiscutivelmente marcante da sua obra, e, porventura, um elemento deveras definitório na questão dos limites entre literaturas de uma mesma base linguística:

«A vinculação da literatura à nacionalidade é que nos obriga a reconhecer como sistemas autónomos, apesar de servidos pela mesma língua, literaturas como a portuguesa, a brasileira, a angolana, a moçambicana, a cabo-verdiana, e a procurar nos temas, nas formas, no estilo de cada uma delas as marcas distintivas

\footnotetext{
${ }^{19} \mathrm{O}$ reducionismo a que é submetida a cultura autóctone ao Norte do Minho, na sua expressäo escrita, origina uma assimetria perante a afirmação e desenvolvimento das potencialidades dessa mesma cultura em Portugal. Com a recuperação (parcial) da própria voz, operada a partir do Ressurdimento galego, é que se irão produzindo as condições para facilitar um diálogo cultural cada vez mais frequente e fluido.

${ }^{20} \mathrm{~A}$ pugna de Isabel e Fernando face à legítima D. Joana, alcunhada «La Beltraneja», sustentada por D. Afonso V de Portugal, divide mais uma vez a nobreza galega, a qual, maioritariamente, aposta pela legitimidade (que poderia implicar, aliás, uma nova aproximação galego-portuguesa), legitimidade afinal perdedora.

${ }^{21}$ In Dicionário de Literatura. Literatura Portuguesa. Literatura Brasileira. Literatura Galega. Estilística Literária. Direcção de Jacinto do Prado Coelho. Figueirinhas, Porto

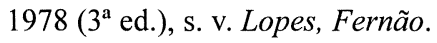


duma experiência colectiva única» ${ }^{22}$.

Nesta linha de pensamento, poderia justificadamente considerar-se Fernão Lopes como prosista exterior à literatura galego-portuguesa, ou, melhor ainda, como o primeiro prosista da literatura portuguesa, ao ser capaz de reflectir na sua história a transformação de um reino numa pátria, simbolizada na revolução de 1383-1385, com o desfecho militar de Aljubarrota. Afirmação da nacionalidade ausente do labor cronístico galego ${ }^{23}$, por óbvias razões históricas, com algumas pinceladas por vezes, isto sim, ligadas a um sentimento primário da terra.

Não se esqueça, contudo, que Fernão Lopes não surge $a b$ ovo mas representa a culminação, brilhante, de toda uma tradição anterior, uma tradição que já apelidámos com bons argumentos de «galego-portuguesa». Mesmo a sua língua literária, alheia ao incipiente gosto latinizante da época, se insere perfeitamente nessa tradição (historiográfica e cavaleiresca). Por outra parte, se o ponto de vista do historiador-narrador é inegavelmente português, a dimensão da matéria historiada excede amplamente este marco, atingindo não só uma projecção galega, mas mesmo peninsular, na sua vertente centro-ocidental.

A produção do sucessor de Fernão Lopes, orientada à consagração da expansão ultramarina em curso, é de teor muito diferente, quase antitético, ao do grande cronista e escritor. Gomes Eanes de Zurara representa, em certo modo, um parêntese na linha iniciada por Fernäo Lopes. $\mathrm{O}$ verdadeiro continuador é, em muitos aspectos, Rui de Pina.

Fernão Lopes constitui, assim, um marco de transição do nível galegoportuguês para o especificamente português, marco que, excluindo Zurara, se poderia prolongar até a Rui de Pina. Em todo o caso, se Zurara não representasse o definitivo limite, este viria dado inadiavelmente pelo surto dos grandes historiadores do séc. XVI, a principiar por João de Bar-

${ }^{22}$ Jacinto do Prado Coelho: A originalidade da literatura portuguesa. Instituto de Cultura Portuguesa, Lisboa 1977, p. 12.

${ }^{23}$ Basta confrontar as respectivas tonalidades de obras próximas no tempo, v. gr., a galega Crónica de 1404 com a chamada Crónica de 1419, portuguesa, e não digamos com a Crónica de D. João I, ou mesmo a Crónica de D. Fernando, de Fernão Lopes. Enquanto a galega é mais uma crónica geral, na linha historiográfica aberta por Afonso X, em Portugal surgem as crónicas particulares do reino (a principiar pela de 1419, que alguns atribuem a Fernão Lopes), que privilegiam os sinais de identidade próprios.

"CUADERNOS DE ESTUDIOS GALLEGOS", Tomo XLI, Fascículo 106, Santiago 1993-94. 
$\operatorname{ros}^{24}$, representante de uma história concebida e desenvolvida segundo moldes clássicos. De todas as formas, eis-nos novamente nos princípios do séc. XVI, como, mutatis mutandis, acontecia no campo da poesia.

E, já nesta altura, acaso não seja despropositada uma referência a Gil Vicente. O grande dramaturgo, que desenvolve a sua acção no primeiro terço do séc. XVI, representa também a culminação, a maturidade, dos processos teatrais ou pára-teatrais da nossa Idade Média, embora não só. Levemente tocado já pelos ares do Renascimento, mas alheio ao teatro clássico propriamente dito, Gil Vicente ocupa na arte dramática, com certo recuo, um lugar equiparável ao de Fernão Lopes no plano historiográfico, um espaço de transição, que de alguma maneira se prolonga, mas também se dilui, nos seus continuadores.

Para findar, uma alusão aos textos de tipo religioso (hagiográficos, teológicos, morais...) e aos de carácter técnico ou utilitário (tratados de alveitaria, equitação, cinegética, culinária...; livro de cambeadores, fragmentos jurídicos, etc.), todos impregnados, por via de regra, de forte didactismo. Cumpre assinalar sobretudo nos segundos a falta de literariedade, e, nos primeiros em especial, pela sua índole, a feição universalizante da sua elaboração e projecção, constituindo assim textos de carácter secundário (pelo menos). Nesta perspectiva, se se quiserem considerar como literatura (que por vezes assoma neles), a língua constitui factor suficiente de classificação, com o que não conviria avançar, nas etiquetas, para além do genérico «galego-português»» ${ }^{25}$.

Em resumo, parece razoável assinalar um amplo período de transição entre a literatura galego-portuguesa e as correspondentes galega e portuguesa plenamente autónomas: desde os meados do séc. XV até ao primeiro quartel do séc. $\mathrm{XVI}^{26}$. A partir do Cancioneiro de Resende, de Rui de

\footnotetext{
${ }^{24}$ Também como linguista marca uma nova etapa, com a publicação da sua Gramática da língua portuguesa, em 1540, data eleita amiúde (com a de 1536, referida à gramática de Fernão de Oliveira) para assinalar o início do período clássico na história da língua.

${ }^{25}$ Veja-se, por exemplo, numa linha de pensamento em parte coincidente, a precisão terminológica que propõe Xosé S. Crespo Pozo, no seu artigo «A Biblia medieval portuguesa compre chamala galego-portuguesa», in Grial, 31 (Janeiro-Março 1971), pp. 95103.

${ }^{26}$ São referências simplesmente aproximativas. O Cancioneiro de Baena foi compilado cerca de 1445, o de Garcia de Resende, como se indicou, em 1516 (ano da morte, aliás, de Fernando o Católico). Em 1526 regressa a Portugal, da Itália, Francisco de Sá de Miranda, decidido à introdução dos novos metros na poesia portuguesa. Gil Vicente, por sua vez, produz a sua obra entre 1502 e 1536, ano este em que é publicada, por Fernão de Oliveira, a primeira gramática da língua do Ocidente peninsular.
} 
Pina, de Gil Vicente, etc., os ecos, cada vez mais débeis, da inicial matriz galaico-lusa esvaem-se definitivamente e assiste-se a um florescimento literário, de primeira ordem, exclusivamente português ${ }^{27}$. Assim, entre a redução da literatura galego-portuguesa à lírica dos Cancioneiros e a adjudicação à literatura galega de autores como $\mathrm{Camões}^{28}$, uma perspectiva mais equilibrada poderá ser a que propomos: a de considerar, sensu strictu, como literatura galego-portuguesa a escrita até 1450 , aproximadamente, e, sensu latu, toda a literatura medieval originada na Galiza e em Portugal até ao advento do Renascimento.

Uma última consideração afigura-se-nos indispensável: para além dos limites que se fixarem, consoante critérios decerto discutíveis, como os agora propostos, impõe-se considerar metodologicamente como um todo, tanto no delineamento da história literária, quanto na exploração e aproveitamento dos seus textos, a literatura medieval surgida a Norte e Sul do rio Minho. Embora só fosse pela língua de que se serve, que não é, como temos visto, a única razão.

${ }^{27}$ A dizer verdade, a literatura galega não atinge, nesta época, qualquer estatuto próprio a respeito do comum galego-português e/ou do específico português. Ela simplesmente desaparece, de facto. A Galiza, incapaz de assumir as rédeas do próprio destino, confia, durante séculos, ao fraterno Portugal o testemunho e a responsabilidade da cultura literária em língua ocidental.

${ }^{28}$ Antonio de la Iglesia: El idioma gallego. Su antigüedad y vida. La Coruña 1886, 3 vols. O episódio de Inês de Castro, tirado dos Lusíadas, está no vol. I, pp. 233-238.

"CUADERNOS DE ESTUDIOS GALLEGOS", Tomo XLI, Fascículo 106, Santiago 1993-94. 